\title{
Response of Escherichia coli minimal ter operon to UVC and auto-aggregation: Pilot study
}

\author{
Lenka Jánošíková ${ }^{\text {Corresp., } 1}$, Lenka Pálková ${ }^{2}$, Dušan Šalát ${ }^{1}$, Andrej Klepanec ${ }^{1}$, Katarina Soltys ${ }^{3,4}$ \\ ${ }^{1}$ Faculty of Health Sciences, University of St. Cyril and Methodius in Trnava, Trnava, Slovak Republic \\ 2 Medirex group, Bratislava, Slovak Republic \\ 3 Department of Microbiology and Virology, Faculty of Natural Sciences, Comenius University in Bratislava, Bratislava, Slovak Republic \\ 4 Comenius University Science Park, Comenius University in Bratislava, Bratislava, Slovak Republic \\ Corresponding Author: Lenka Jánošíková \\ Email address: lenka.janosikova@ucm.sk
}

\begin{abstract}
Aim. The study of minimal ter operon as a determinant of tellurium resistance $\left(T e^{R}\right)$ is important for the purpose of confirming the relationship of these genes to the pathogenicity of microorganisms. The ter operon is widespread among bacterial species and pathogens, implicated also in phage inhibition, oxidative stress and colicin resistance. So far, there is no experimental evidence for the role of the Escherichia coli (E. coli) minimal ter operon in ultraviolet C (UVC) resistance, biofilm formation and autoaggregation. To identify connection with UVC resistance of the minimal ter operon, matched pairs of Terpositive and -negative $E$. coli cells were stressed and differences in survival and whole genome sequence analysis were performed. This study was aimed also to identify differences in phenotype of cells induced by environmental stress.
\end{abstract}

Methods. In the current study, a minimal ter operon (terBCDE $\triangle F$ ) originating from the uropathogenic strain E. coli KL53 was used. Clonogenic assay was the method of choice to determine cell reproductive death after treatment with UVC irradiation at certain time intervals. Bacterial suspensions were irradiated with $254 \mathrm{~nm}$ UVC-light (germicidal lamp in biological safety cabinet) in vitro. UVC irradiance output was $2.5 \mathrm{~mW} / \mathrm{cm}^{2}$ (calculated at the UVC device aperture) and plate-lamp distance of $60 \mathrm{~cm}$. DNA damage analysis was performed using shot-gun sequencing on Illumina MiSeq platform. Biofilm formation was measured by a crystal violet retention assay. Auto-aggregation assay was performed according to the Ghane et al. (2020).

Results. A large fraction of Ter-positive E. coli cells survived treatment with 120-s UVC light (300 $\mathrm{mJ} / \mathrm{cm}^{2}$ ) compared to matched Ter-negative cells; 5-fold higher resistance of Ter-positive cells to UVC dose ( $p=0.0007)$. Moreover, UVC surviving Ter-positive cells showed smaller mutation rate as Ternegative cells. The study demonstrated that a 1200-s exposure to UVC $\left(3000 \mathrm{~mJ} / \mathrm{cm}^{2}\right)$ was sufficient for $100 \%$ inhibition of growth for all the Ter-positive and -negative E. coli cells. The Ter-positive strain exhibited of $26 \%$ higher auto-aggregation activities and was able to inhibit biofilm formation over than Ter- negative strain $(* * * * P<0.0001)$.

Conclusion. Our study shows that Ter-positive cells display lower sensitivity to UVC radiation, corresponding to a presence in minimal ter operon. In addition, our study suggests that also autoaggregation ability is related to minimal ter operon. The role of the minimal ter operon (terBCDE $\triangle F$ ) in resistance behavior of $E$. coli under environmental stress is evident. 


\section{Response of Escherichia coli minimal ter operon to}

3 UVC and auto-aggregation: Pilot study

4

5

6

7

8

9

10

11

Lenka Jánošíková ${ }^{1}$, Lenka Pálková ${ }^{2}$, Dušan Šalát ${ }^{1}$, Andrej Klepanec ${ }^{1}$, Katarina Soltys ${ }^{3,4}$

${ }^{1}$ Faculty of Health Sciences, University of Ss. Cyril and Methodius in Trnava, Trnava, Slovak Republic

${ }^{2}$ Medirex group, Bratislava, Slovak Republic

${ }^{3}$ Department of Microbiology and Virology, Faculty of Natural Sciences, Comenius University in Bratislava, Bratislava, Slovak Republic

${ }^{4}$ Comenius University Science Park, Comenius University in Bratislava, Bratislava, Slovak Republic

Corresponding Author:

Lenka Jánošíková ${ }^{1}$

Námestie J. Herdu 2, Trnava, 921 01, Slovak Republic

Email address: lenka.janosikova@ucm.sk

\section{Abstract}

Aim. The study of minimal ter operon as a determinant of tellurium resistance $\left(\mathrm{Te}^{\mathrm{R}}\right)$ is important for the purpose of confirming the relationship of these genes to the pathogenicity of microorganisms. The ter operon is widespread among bacterial species and pathogens, implicated also in phage inhibition, oxidative stress and colicin resistance. So far, there is no experimental evidence for the role of the Escherichia coli (E. coli) minimal ter operon in ultraviolet $\mathrm{C}$ (UVC) resistance, biofilm formation and auto-aggregation. To identify connection with UVC resistance of the minimal ter operon, matched pairs of Ter-positive and -negative $E$. coli cells were stressed and differences in survival and whole genome sequence analysis were performed. This study was aimed also to identify differences in phenotype of cells induced by environmental stress.

Methods. In the current study, a minimal ter operon (ter $B C D E \triangle F)$ originating from the uropathogenic strain $E$. coli KL53 was used. Clonogenic assay was the method of choice to determine cell reproductive death after treatment with UVC irradiation at certain time intervals. Bacterial suspensions were irradiated with $254 \mathrm{~nm}$ UVC-light (germicidal lamp in biological safety cabinet) in vitro. UVC irradiance output was $2.5 \mathrm{~mW} / \mathrm{cm}^{2}$ (calculated at the UVC device aperture) and plate-lamp distance of $60 \mathrm{~cm}$. DNA damage analysis was performed using shot- 
39

40

41

42

43

44

45

46

47

48

49

50

51

52

53

54

55

56

57

58

59

60

61

62

63

64

65

66

67

68

69

70

71

72

73

74

75

76

77

78

gun sequencing on Illumina MiSeq platform. Biofilm formation was measured by a crystal violet retention assay. Auto-aggregation assay was performed according to the Ghane et al. (2020).

Results. A large fraction of Ter-positive E. coli cells survived treatment with 120-s UVC light $\left(300 \mathrm{~mJ} / \mathrm{cm}^{2}\right)$ compared to matched Ter-negative cells; $\sim 5$-fold higher resistance of Ter-positive cells to UVC dose $(p=0.0007)$. Moreover, UVC surviving Ter-positive cells showed smaller mutation rate as Ter-negative cells. The study demonstrated that a 1200 -s exposure to UVC $\left(3000 \mathrm{~mJ} / \mathrm{cm}^{2}\right)$ was sufficient for $100 \%$ inhibition of growth for all the Ter-positive and -negative E. coli cells. The Ter-positive strain exhibited of $26 \%$ higher auto-aggregation activities and was able to inhibit biofilm formation over than Ter- negative strain $(* * * * \mathrm{P}<0.0001)$.

Conclusion. Our study shows that Ter-positive cells display lower sensitivity to UVC radiation, corresponding to a presence in minimal ter operon. In addition, our study suggests that also autoaggregation ability is related to minimal ter operon. The role of the minimal ter operon (ter $B C D E \triangle F)$ in resistance behavior of $E$. coli under environmental stress is evident.

\section{Introduction}

Little is known about the biochemical activities and biological function of the TerB, TerC, TerD and TerE proteins, that are determined by genes of the minimal ter operon encoded by a plasmid. To this date, there is no study of resistance to UVC radiation, biofilm formation and autoaggregation in tellurium resistance $\left(\mathrm{Te}^{\mathrm{R}}\right) E$. coli cells.

Ultraviolet (UV) irradiation is electromagnetic irradiation, where the UVC spectrum, is absorbed by the nucleic acids (Gurzadyan et al., 1995) producing several types of damage that interfere among other with replication and transcription of DNA. UV light promot a major and minor photoproduct formation. The major photoproducts of DNA are cyclobutane pyrimidine dimers (CPDs) and pyrimidine-(6,4)-pyrimidone photoproducts (6-4PPs) (Tropp, 2008), where covalent bonds are present between adjacent pyrimidines on the same DNA strand (Pirnie et al., 2006). Moreover, the minor photoproducts of DNA are Dewar photoproducts, TA* photoproducts, $\mathrm{AA}^{*}$ photoproducts and Porschke photoproducts with a very small quantum yield production (Siede et al., 2005). Other types of UV damage are also known, such as protein-DNA cross-links, DNA-DNA cross-links, single strand breaks and double strand breaks. However, pyrimidine dimers are the most common damage resulting from UV light (Pirnie et al., 2006). If UV-induced damage is not repaired or eliminated from DNA, it may lead to mutagenesis, cellular transformation, and cell death. Even if the lesion is removed, the result can be a mutation (Tropp, 2008). This was the reason why we started looking for some connection between the potential increased UVC resistance and mutation rate of the cells.

It is well known that $\mathrm{UV}$ radiation is used to inactivate microorganisms, i.e. UV disinfection. Ultraviolet disinfection can be used to disinfect air, water, wastewater, laboratory equipment, medical instruments, food and beverages. Therefore, it is extremely important to study the phenomenon of UVC resistance. Dai et al. (2012) discussed the potential of UVC irradiation as a different concept to standard methods used to treat localized infections. The 
79

80

81

82

83

84

85

86

87

88

89

90

91

92

93

94

95

96

97

98

99

100

101

102

103

104

105

106

107

108

109

110

111

112

113

114

115

116

117

118

119

gradual emergence of populations of antibiotic-resistant bacteria has become a major public health problem. Antibiotic resistance has led to the search for alternative antimicrobial approaches to which, microorganisms will not be easily able to develop resistance. On the other hand, the existence of UVC-resistant microorganisms and the resistance mechanisms themselves should be considered. For instance, the multiple extremes resistant bacterium Deinococcus radiodurans (D. radiodurans) is able to withstand harsh condition, such as UV radiation (Ott et al., 2017).

Burian et al. (1990) identified during testing of the group of clinical isolates a uropathogenic strain of $E$. coli KL53 resistant to tellurite. The ter operon (terXYW and terZABCDEF) has been found on a large conjugative plasmid pTE53 and the $5 \mathrm{~kb}$ region of ter operon was cloned into the low copy plasmid pACYC184. This plasmid contained minimal ter operon and was marked as pLK18 (Burian et al., 1998), which we used in our work. The genes from the large conjugative plasmid pTE53 of E. coli strain KL53: terB, terC, terD and terE are essential for conservation of the $\mathrm{Te}^{\mathrm{R}}$ whereas the gene ter $F$ is not important in this respect (Kormutakova et al., 2000). It is important to note that homologous genes have been found in bacteria like E. coli O157:H7, D. radiodurans (Taylor et al., 2002), Shigella flexneri, Yersinia pestis (Taylor, 1999), Klebsiella pneumoniae (Chen et al., 2004), Vibrio cholerae, Proteus mirabilis (Toptchieva et al., 2003), etc. of which the vast majority are pathogenic microorganisms and cause serious diseases in humans worldwide (Lim et al. 2010; Schroeder and Hilbi, 2008; Demeure et al., 2019; Struve and Krogfelt, 2004; Nelson et al., 2009; Chen et al., 2012).

It is assumed that the TerC-TerB complex can be associated with biochemical activities of proteosynthesis, C4-dicarboxylate transport, ATPase/chaperone activity and inner membrane stress response in bacteria (Turkovicova et al., 2016). On the other hand, TerC from Arabidopsis thaliana (Eukaryote) plays a crucial role in prothylakoid membrane biogenesis and thylakoid formation in early chloroplast development (Kwon \& Cho 2008). According to Grant \& Tsang (1990), TerD and TerE proteins share massive similarity with a cyclic AMP binding protein from Dictyostelium discoideum (Eukaryote). The results suggest that TerD family of eukaryotic homologs of TerD protein can bind soluble ligands, such as cAMP. Contrarily, a structural study from Klebsiella pneumoniae showed that TerD binds $\mathrm{Ca}(2+)$. These results suggest that some form of $\mathrm{Ca}(2+)$ signaling plays a crucial role in $\mathrm{Te}^{\mathrm{R}}$ (Pan et al., 2011). Evidence from the Streptomyces coelicolor suggests that this domain plays an important role in the adaptation of redox stress and calcium homeostasis in bacteria (Daigle et al., 2015). However, can all these known and unknown properties of Ter proteins (TerB, TerC, TerD and TerE) have an effect on the increased UVC resistance of cells?

Characteristic phenotype of cells bearing ter genes (ter $Z$, ter $A$, terB and ter $C$ ) reported as influencing the potassium tellurite resistance present on the IncHI2 plasmid R478 in E. coli, is a filamentous morphology, indicated inhibition of cell division (Whelan et al. 1997). Similarly, Ponnusamy and Clinkenbeard (2015) observed that terZAB genes mediated filamentous cellular morphology of Yersinia pestis, during macrophage infections, whereas terCDE confers tellurite resistance. These studies led to speculate that these genes are part of a bacterial adaptive strategy 
120

121

122

123

124

125

126

127

128

129

130

131

132

133

134

135

136

137

138

139

140

141

142

143

144

145

146

147

148

149

150

151

152

153

154

155

156

157

158

159

160

which also includes morphological changes of the cell to associated stress. In our previous study, we found up-regulation of the tryptophanase in Ter-negative (control) cells at a "sub-lethal" concentration of tellurite $3.9 \mu \mathrm{mol} . \mathrm{l}^{-1}$ (Aradská et al., 2013). According to a study by KuczyńskaWiśnik et al. (2010) due to oxidative stress and over-expression of tryptophanase, which catalyzed indole synthesis, biofilm formation in E. coli was inhibited.

Therefore, we were interested in the connection between the Ter-positive E. coli cells and biofilm formation and/or auto-aggregation as a possible defense mechanism against stress.

The aim of this pilot study was also to analyze the survival of Ter-positive and -negative E. coli cells and determine the DNA damage (mutation rate) after three different doses of UVC radiation.

\section{Materials \& Methods}

\section{Bacterial strains and cultivation conditions}

All bacterial strains and plasmids used in this study came from the collection of microorganisms of the Department of Molecular Biology, Faculty of Natural Sciences, Comenius University in Bratislava. The strains E. coli BL21 carrying plasmids pLK18 and pACYC184 were used for plasmid DNA preparation. Ter-positive strain E. coli BL21(DE3) bearing plasmid pLK18 and Ter-negative strain E. coli BL21 (DE3) carrying plasmid pACYC184 were used. Ter-positive as well as -negative cells were grown in LB medium supplemented with chloramphenicol. As an internal control of the biofilm formation methodology, we used the bacterium Cronobacter malonaticus 161007/29.

\section{Plasmid DNA preparation}

Plasmid DNA was extracted from cells with “QIAprep Spin Miniprep Kit” (Qiagen, Hilden, Germany) according to manufacturer's instructions - Isolation from cells. The resulting DNA samples were visualized on a 1\% agarose gel stained with Ethidium Bromide. Totally 100 ng of bacterial DNA quantified spectrophotometrically with NanoDrop 1000 Spectrophotometer (Thermo Fisher Scientific, Waltham, MA, USA) was used for electroporation.

\section{Preparation of competent cells}

Overnight culture of $E$. coli BL21(DE3) was diluted 1:100 for growth in LB (LauriaBertani) broth. Cells were grown to an $\mathrm{OD}_{600} 0.5$ at $37^{\circ} \mathrm{C}$ and were pelleted by centrifugation at 6000 RPM for $10 \mathrm{~min}$. Cells were resuspended in cold sterile $\mathrm{ddH}_{2} \mathrm{O}$. This treatment was repeated four times. After brief centrifugation, cell pellets were resuspended in $10 \%$ glycerol $(0.3$ $\mathrm{mL}$ ). Finally, cells were transferred to microcentrifuge tube. For long-term storage of competent cells, cells were frozen immediately in a dry ice/ethanol bath and stored at $-70{ }^{\circ} \mathrm{C}$ until needed.

\section{Electroporation}

Electroporation was carried out using a BioRad gene Pulser. One hundred ng of DNA was mixed with electrocompetent cell and transferred to the cuvette. Electroporation conditions 
161

162

163

164

165

166

167

168

169

170

171

172

173

174

175

176

177

178

179

180

181

182

183

184

185

186

187

188

189

190

191

192

193

194

195

196

197

198

199

200

201

were as follows $125 \Omega, 25 \mu \mathrm{F}, 2.5 \mathrm{kV}$ and 4,9 msec. After electroporation, $1 \mathrm{~mL} \mathrm{LB}$ was added to the cuvette. Cells were then transferred to culture tube for $1 \mathrm{~h}$ growth with shaking at $37^{\circ} \mathrm{C}$. Then, $0.1 \mathrm{~mL}$ of cells was spread on LB agar selective plates with chloramphenicol and incubated at $37^{\circ} \mathrm{C}$ overnight.

\section{Ultraviolet $\mathbf{C}$ irradiation studies}

Two-hundred microliters of an overnight culture Ter-positive and -negative cells were used to inoculate $20 \mathrm{~mL}$ of $\mathrm{LB}$ medium. When the $\mathrm{OD}_{600}$ reached 0.6 , cells grew for another $24 \mathrm{~h}$ to reach stationary growth phase. In the stationary growth phase, $5 \mathrm{~mL}$ solution was placed in sterile $55 \mathrm{~mm}$ diameter Petri dishes which were set on a shaking platform at 80 RPM. The cells were irradiated with $254 \mathrm{~nm}$ UVC-light (germicidal lamp in biological safety cabinet MSCadvantage TM Class II BSC Thermo Scientific) in an open (no lid on) media plates for $0 \mathrm{~s}, 120 \mathrm{~s}$, $1200 \mathrm{~s}$. UVC irradiance output was $2.5 \mathrm{~mW} / \mathrm{cm}^{2}$ (calculated at the UVC device aperture) and plate-lamp distance of $60 \mathrm{~cm}$. Total exposure was calculated using the irradiance output multiplied by the amount of time they were irradiated. Immediately after irradiation, at each UVC dose $\left(0.0 \mathrm{~mJ} / \mathrm{cm}^{2}, 300 \mathrm{~mJ} / \mathrm{cm}^{2}\right.$ and $\left.3000 \mathrm{~mJ} / \mathrm{cm}^{2}\right)$, sample was serially diluted in LB medium with decimal dilution and $0.01 \mathrm{~mL}$ of $1: 10,000$ dilution was plated on LB agar with chloramphenicol. Cells were incubated on $37^{\circ} \mathrm{C}$ for $24 \mathrm{~h}$ in dark and counted. For statistical reasons, three plates were needed for each dilution series. The following equation was used to calculate the number of Colony forming units (CFU) per $\mathrm{mL}$ from the original sample: $\mathrm{CFU} / \mathrm{mL}$ $=$ number of colonies / volume of culture plated $(\mathrm{mL}) \mathrm{x}$ dilution factor. The triplicates were averaged and CFU were computed. Experiments were performed in biological "four replicates". Percentual survival was calculated using the following equation: Percentual survival $=(\mathrm{CFU}$ of exposed sample/ CFU of unexposed sample) x 100. The rest of the irradiated cells was collected by centrifugation (8000 RPM), and stored as frozen pellets at $-20{ }^{\circ} \mathrm{C}$, to be used for DNA isolation and whole genome sequencing.

\section{Statistical analyses}

All data for statistical analysis were obtained from minimum of three independent experiments. Averages and standard deviations were reported. Differences between experimental groups were set using unpaired t-Test: two-sample assuming equal variances or one-way ANOVA. $P$-values of 0.05 or less were considered statistically significant $(* * * P<0.001, * * * * P$ $<0.0001$ ). All statistical analyses were performed with GraphPad Prism 6.0 software (GraphPad Software Inc., San Diego CA, USA).

\section{Crystal Violet Assay for Biofilm Formation}

Quantification of biofilm formation was assayed according to the published method with minor modifications (Ghane et al., 2020). Bacterial cells (Te-R and control) with $\mathrm{OD}_{600}=2$ were diluted with fresh LB medium (1:100) and $200 \mu$ of diluted suspension was poured into the 96well plates. The plates were incubated stationary at $37^{\circ} \mathrm{C}$ for $24 \mathrm{~h}$ to create biofilm. Each well was gently rinsed 3 times with $150 \mu$ sterile PBS, $\mathrm{pH} 7.2$ to remove all planktonic bacteria. The

Peer] reviewing PDF | (2020:08:51726:3:0:NEW 24 Feb 2021) 
202

203

204

205

206

207

208

209

210

211

212

213

214

215

216

217

218

219

220

221

222

223

224

225

226

227

228

229

230

231

232

233

234

235

236

237

238

239

240

241

242

243

244

attached cells were fixed with $150 \mu 1$ methanol and dried up at room temperature. After that, 150 $\mu 1$ of $0.1 \%$ Crystal Violet solution (Sigma-Aldrich) was added to each well for 15 minutes to stain biofilm. The excess of unbound dye was removed with MilliQ water. Retained crystal violet was solubilized by the addition of 150 of $\mu 196 \%$ ethanol for 15 minutes, and absorbance was measured at $570 \mathrm{~nm}$ using spectrophotometer (Beckman Coulter). The experiments were performed in six technical replicates and repeated three times (Cronobacter malonaticus 161007/29) or six times (control, Te-R). As an internal control of the biofilm formation methodology, we used the bacterium Cronobacter malonaticus 161007/29.

\section{Auto-aggregation assay}

Auto-aggregation assays were performed according to the published method with slight modifications (Ghane et al., 2020). Overnight cultures of bacterial cells (Te-R and control) were centrifuged at $6000 \mathrm{~g}$ for $10 \mathrm{~min}$ and the pellets were resuspended $2 \mathrm{ml}$ of in $\mathrm{PBS} \mathrm{pH}=7.4\left(\mathrm{OD}_{600}\right.$ $=0.5)$. The cultures were incubated for $24 \mathrm{~h}$ at $25^{\circ} \mathrm{C}$ and the absorbance was measured at $600 \mathrm{~nm}$ using spectrophotometer (Varioskan, ThermoFisher-Scientific) before $(0 \mathrm{~h})$ and after $(24 \mathrm{~h})$ incubation. The results were represented by two independent experiments performed with three technical replicates. The auto-aggregation percentage was determined as $\left[\left(\mathrm{A}_{0}-\mathrm{A}_{1}\right) / \mathrm{A}_{0}\right] \mathrm{x} 100$ where $A_{0}$ represented the absorbance of the culture at $0 \mathrm{~h}$ and $A_{1}$ represents the absorbance of the culture after $24 \mathrm{~h}$ according to the published method (Wang et al., 2015).

\section{Whole-genome sequencing and sequence analysis}

Total DNA was isolated by DNeasy Blood \& Tissue kit (Qiagen, Hilden, Germany) according to manufacturer's instructions. Totally $1 \mathrm{ng}$ of bacterial DNA quantified fluorometrically with Qubit 2.0 Fluorometer (Thermo Fisher Scientific, Waltham, MA, USA) was used as template for transposon-based library preparation by Nextera XT library preparation kit (Illumina, San Diego, CA, USA), according to standard protocol. After low-cycle indexing pcr amplification with Nextera XT Index Kit (Illumina, San Diego, CA, USA) and purification using Agencourt AMPure XP beads (Beckman Coulter, Brea, USA) for size-selection, libraries were quantified with Qubit dsDNA HS Assay Kits (Thermo Fisher Scientific, Waltham, MA, USA) and the average fragment size was determined using Agilent High Sensitivity DNA Kit (Agilent Technologies, Waldbronn, Germany). Final libraries were pooled together in equimolar ratio and analysed using paired-end (2x250) sequencing on Illumina MiSeq platform (Illumina, San Diego, California, USA). Sequencing data were imported into CLC Genomics Workbench Version 9.5.2 (Qiagen). Each sequence of sample was treated by merging and trimming (0.01) and reads shorter than 50 nucleotides were discarded. Trimmed reads were mapped to reference genome of Escherichia coli BL21(DE3) (NC_012971). Aligned reads were deduplicated and locally realigned with default settings. Variant calling was performed using fixed ploidy variant detection tool with fixed ploidy 1 , required variant probability $90 \%$ and minimum frequency $20 \%$.

\section{Determination of mutation rate}

The mutation rate $(\mu)$ was determined according Pope et al. (2008) by using the equation $\mu=\left[\left(r_{2} / N_{2}\right)-\left(r_{1} / N_{1}\right)\right] \times \ln \left(N_{2} / N_{1}\right)=\left(f_{1}-f_{2}\right) \times \ln \left(N_{2} / N_{1}\right)$, where $r_{1}$ is the observed number of 
245 mutants at time point $1, r_{2}$ is the observed number of mutants at the next time point, and $N_{1}$ and $246 N_{2}$ are the numbers of cells at time points 1 and 2, respectively, while $f_{1}$ and $f_{2}$ are the mutant

247 frequencies at points 1 (which was 0 seconds) and 2 (which was 120 seconds). The results were 248 then compared.

249

250

251

252

253

254

255

256

257

258

259

260

261

262

263

264

265

266

267

268

269

270

271

272

273

274

275

276

277

278

279

280

281

282

283

284

\section{Results and discussion}

We have selected the appropriate strain of E. coli BL21 (DE3) (NC_012971) according to the availability of the reference genome in the database, to facilitate work with the sequencing data. The bacterial strains and plasmids were obtained from the collection of microorganisms of the Department of Molecular Biology, Comenius University in Bratislava, Faculty of Natural Sciences.

Isolation of the plasmids (pLK18 - ter+ and pACYC184 - ter-) was followed by electroporation into the appropriate strain mentioned above. Consequently, we have prepared Ter-positive cells and Ter-negative cells to help us compare their UVC treatment response. The bacterial resistance and sensitivity to tellurite provided by the above-mentioned plasmids was already proved in our previous work (Aradska et al., 2013).

Triplicates of bacterial cultures at Petri dishes were exposed to $0 \mathrm{~s}\left(0.0 \mathrm{~mJ} / \mathrm{cm}^{2}\right), 120 \mathrm{~s}(300$ $\left.\mathrm{mJ} / \mathrm{cm}^{2}\right)$ and $1200 \mathrm{~s}\left(3000 \mathrm{~mJ} / \mathrm{cm}^{2}\right)$ of UVC dose calculated at the UVC device aperture and plate-lamp distance of $60 \mathrm{~cm}$ in laboratory biological safety cabinet. In the stationary phase of growth, neither Ter-positive nor Ter-negative cells survived after $3000 \mathrm{~mJ} / \mathrm{cm}^{2}$ of $\mathrm{UVC}$ radiation. Contrarily, Ter-positive cells showed an average of 5-fold higher resistance to UVC radiation compared to Ter-negative cells after $300 \mathrm{~mJ} / \mathrm{cm}^{2}$ of UVC exposure. The percentage of survival was based on colony forming unit measurements, of Ter-negative and Ter-positive cells. The percentage of survived Ter-negative cells $(M=4.00, \operatorname{SEM} \pm 1,780, \mathrm{n}=4)$ was smaller than the percentual survival of the Ter-positive group $(\mathrm{M}=20.25, \mathrm{SEM} \pm 2,287, \mathrm{n}=4)$. This difference was considered statistically significant, $\mathrm{t}(6)=5.60, \mathrm{p}=0.0007$ (One-tailed) (Fig. 1;

Supplemental raw data 1). At an irradiance of $2.5 \mathrm{~mW} / \mathrm{cm}^{2}$ calculated according to the lamp aperture, $120 \mathrm{~s}$ UVC irradiation time reduced bacterial colony forming units (CFUs) by $79.75 \%$ in Ter-positive and by $96 \%$ in Ter-negative cells in liquid LB medium. These results indicate that the Ter-negative cells have reduced ability to survive following UVC exposure. We presumed that the minimal ter operon ( $\operatorname{ter} B C D E \triangle F$ ) may be involved in increased UVC resistance of $E$. coli, due to the fact that it is responsible for many other resistances such as tellurium, oxidative stress, colicin resistance and is also implicated in phage inhibition. Our assumptions have been partially confirmed in this work, in the context that this was only pilot study.

An analysis of the whole bacterial genome in CLC software enabled to reveal that cells after $120 \mathrm{~s}\left(300 \mathrm{~mJ} / \mathrm{cm}^{2}\right) \mathrm{UVC}$ irradiation show a higher proportion of mutations (insertion and SNV) in Ter-negative cells. In the $c y n X$ (cyanate MFS transporter) gene, insertion of T occurred at position 330099, in the $\operatorname{glgC}$ (glucose-1-phosphate adenylyltransferase) gene a single nucleotide variation of $\mathrm{G}$ to $\mathrm{A}$ occurred at position 343170 , but these mutations were missense. No changes were found in Ter-positive cells after irradiation, a deletion present in the cells was 
285 present even before irradiation. In the $p c n B$ (polynucleotide adenylyltransferase PcnB) gene, 286 deletion of $\mathrm{T}$ occurred at position 160821, also this mutation was missense (Table 1). All 287 sequencing data has been deposited in a public database GenBank under the accession no. of 288 BioProject PRJNA655930 (https://www.ncbi.nlm.nih.gov/bioproject/?term=prjna655930). This

289

290

291

292

293

294

295

296

297

298

299

300

301

302

303

304

305

306

307

308

309

310

311

312

313

314

315

316

317

318

319

320

321

322

323

324 project consists of sequences for Ter-positive cells after $120 \mathrm{~s}$ irradiation (BioSample: SAMN15762301; Sample name: 8LT-Bl21-minTer-120s; SRA: SRS7167470), Ter-negative cells after 120 s irradiation (BioSample: SAMN15762280; Sample name: 3LT-Bl21-ctrl-120s; SRA: SRS7167466), Ter-negative cells after 0 s irradiation (BioSample: SAMN15762266; Sample name: 1LT-B121-ctrl-0s; SRA: SRS7167437) and Ter-positive cells after 0 s irradiation (BioSample: SAMN15762300; Sample name: 5LT-Bl21-minTer-0s; SRA: SRS7171211). We determined the mutation rate of the cells after $120 \mathrm{~s}$ UVC irradiation using the above equation. The mutation rate of Ter-negative cells was higher (161.72) than the mutation rate of Terpositive cells (0).

Although this is the first study of the E. coli minimal ter operon in the role of UVC resistance, studies in D. radiodurans are known to reveal the association of Ter proteins with UVC. To understand the functions of individual genes and cellular systems in D. radiodurans as well as their relationship with other organisms Makarova et al. (2001) undertook a detailed computational analysis of the $D$. radiodurans genome. Expansion of proteins of the TerDEXZ/CABP family in Deinococcus is interesting because some of these proteins could confer resistance to a variety of DNA-damaging agents, including methyl methanesulfonate, mitomycin C, heavy-metal cations, and UV (Azeddoug \& Reysset, 1994; Jobling \& Ritchie, 1988) and other forms of stress (Antelmann et al., 1997). This family si likely to be releated to stress response (Makarova et al., 2001). In another work, Karlin \& Mrazek (2001) proposed that Tellurium resistance protein TerD is one of the proteins, that help intrinsically in maintaining the survival and stability of the $D$. radiodurans cell when exposed to severe conditions of UV radiation. Moreover, TerD protein can potentially stand out in the manifold detoxification facilities that neutralize and remove free oxygen radicals and other toxic substances. Their approach was based on predicting gene expression levels related to codon usage differences among gene classes. In this context, $\operatorname{ter} D$ was identified as a highly expressed gene. Further, Sweet \& Moseley (1974) investigated that in exponential phase, D. radiodurans is 33 -fold more resistant to UV than is E. coli. Kirsko and Radman (2010) reported that $4 \%$ of $E$. coli cells ( $E$. coli MG1655 wild type, E. coli $\Delta$ recA:: kan, E. coli CB1000, E. coli CB2000, E. coli CB founder strain (MG1655)) survived after irradiation with a dose of approximately $100 \mathrm{~J} / \mathrm{m}^{2}(1000$ $\mathrm{mJ} / \mathrm{cm}^{2}$ ). It is important to emphasize that the strains of bacteria used in the study did not contain ter genes. In our study, only $4 \%$ of $E$. coli cells survived, that did not contain ter genes, but at a much lower dose, the dose of $30 \mathrm{~J} / \mathrm{m}^{2}\left(300 \mathrm{~mJ} / \mathrm{cm}^{2}\right)$ calculated at the UVC device aperture (plate - lamp distance was $60 \mathrm{~cm}$ ). This more than three-fold difference between irradiation doses may be due to differences in the design of the experiment. In our case, we irradiated the cells with constant shaking in a liquid medium. Another study identified, that oxidative stress-responsive proteins within tellurium resistance operon TerB (DR2220) and TerD (DR2221) were 
325

326

327

328

329

330

331

332

333

334

335

336

337

338

339

340

341

342

343

344

345

346

347

348

349

350

351

352

353

354

355

356

357

358

359

360

361

362

363

364

365

366

367

upregulated in cells of $D$. radiodurans exposed to UVC/vacuum conditions and analysed by an integrative proteometabolomic approach (Ott et al., 2017). In context of previous findings, we can assume that ter genes do not play a role directly in repairing DNA damage caused by UVC radiation, but rather provide increased resistance to oxidative stress caused by UVC radiation. Thus, they could indirectly provide a reduction of DNA damage.

Furthermore, a significant difference between Ter-positive (Te-R) cells and Ter-negative (control) cells in biofilm formation and auto-aggregation was demonstrated in our study for the first time. We hypothesized that some of given phenotypes could contribute to increased resistance to environmental stressors in Ter-positive (Te-R) cells. We found a deficiency in biofilm formation in Ter-positive (Te-R) cells compared to Ter-negative cells (control) $(* * * * \mathrm{P}<$ 0.0001) (Fig.2) (Supplemental raw data 2). As an internal control of the method of biofilm formation, we used the bacterium Cronobacter malonaticus 161007/29 (C. malonaticus 161007/29), which is well known to form biofilm on various surfaces (Ye et al., 2018). Overall, the mean $\mathrm{OD}_{570}$ for $C$. malonaticus $161007 / 29$ was significantly higher than the mean $\mathrm{OD}_{570}$ for Ter-positive (Te-R) and Ter-negative cells (control) $(* * * * \mathrm{P}<0.0001)$ (Fig.3) (Supplemental raw data 3 ).

In this study, auto-aggregation ability of E. coli strains (Ter-positive and control) were investigated. Ter-positive strain showed strong ability of auto-aggregation (96.09\%) in comparison to the Ter-negative (control) strain (69.53\%) (Supplemental raw data 4). However, the exact mechanism for ensuring auto-aggregation in Ter-positive cells is currently unknown. The auto-aggregation phenotype of the Ter-positive cells can be a part of defence machinery against environmental stress conditions. The association between auto-aggregation and environmental stress defence was also demonstrated in the experiment of the tellurium resistant tmp-expressing E. coli cells (Prigent-Combaret et al., 2012).

Bacterial biofilm formation is often preceeded by the formation of cell auto-aggregates (Trunk et al., 2018). However, there are exceptions where cells form auto-aggregates but do not form a biofilm like in the study of Hiramatsu et al. (2016). In this study the BipA mutant of Bordetella holmesii exhibited the strong auto-aggregation phenotype, but failed to form biofilms. Bordetella intermediate protein A (BipA) plays a big role in preventing auto-aggregation and indirectly promoting biofilm formation in Bordetella holmesii. Another example is Burkholderia pseudomallei 08 , where auto-aggregation is mediated by pilA in a temperature-regulated manner. On the other hand, pilA reduces biofilm formation by Burkholderia pseudomallei 08 (Boddey et al., 2006).

It is already well known that various morphological changes (auto-aggregates and/or biofilms) of bacterial cells affect the survival of these microorganisms under stressful conditions (de Carvalho, 2017; Caceres et al., 2014; Kostakioti et al., 2013; Haaber et al., 2012; Anderson \& O'Toole, 2008; Hall-Stoodley et al. 2004; Elasri \& Miller, 1999).

In conclusion, our study shows that the $E$. coli minimal ter operon does show an increased ability of cells to survive UVC irradiation and smaller mutation rate after $120 \mathrm{~s}$. We have clearly shown that Ter-positive cells form auto-aggregates to an increased extent but are deficient in biofilm formation under the indicated conditions. From these findings, we can assume that the formation of auto-aggregates provides a physiological advantage to Ter-positive cells in comparison with Ter-negative (control) cells under stress conditions. However, the exact

PeerJ reviewing PDF | (2020:08:51726:3:0:NEW 24 Feb 2021) 
368

369

370

371

372

373

374

375

376

377

378

379

380

381

382

383

384

385

386

387

388

389

390

391

392

393

394

395

396

397

398

399

400

401

402

403

404

405

406

407

408

409

molecular mechanism of increased UVC resistance and increased auto-aggregation is not known in this case.

\section{Conclusions}

Our pilot study shows that Ter-positive cells display lower sensitivity to UVC radiation, corresponding to a presence in minimal ter operon. Ter-positive cells showed an average of 5fold higher resistance to UVC radiation compared to Ter-negative cells after $120 \mathrm{~s}\left(300 \mathrm{~mJ} / \mathrm{cm}^{2}\right)$ of UVC exposure calculated at the UVC device aperture and plate-lamp distance of $60 \mathrm{~cm}$. As expected, we found that neither Ter-positive nor Ter-negative cells survived after $1200 \mathrm{~s}$ (3000 $\mathrm{mJ} / \mathrm{cm}^{2}$ ) of UVC radiation also calculated at the UVC device aperture and plate-lamp distance of $60 \mathrm{~cm}$, which is commonly used to disinfect the laminar box. The role of the E. coli minimal ter operon in higher UVC resistance is evident. Percentual survival was considered statistically significant, $\mathrm{t}(6)=5.60, \mathrm{p}=0.0007$. At an irradiance of $2.5 \mathrm{~mW} / \mathrm{cm}^{2}$ calculated according to the lamp aperture, $120 \mathrm{~s}$ UVC irradiation time reduced bacterial colony forming units (CFUs) by $79.75 \%$ in Ter-positive and by $96 \%$ in Ter-negative cells in liquid LB medium. The effect of UVC radiation on the DNA damage at the whole genome level exhibited smaller mutation rate in Ter-positive cells than in Ter-negative cells. The Ter-positive strain exhibited $26 \%$ higher autoaggregation activities and were able to inhibit biofilm formation more than Ter- negative strain (**** $\mathrm{P}<0.0001)$. Our findings suggest that auto-aggregation ability is related to minimal ter operon. We hypothesize that the auto-aggregation phenotype may provide to Ter-positive cells a physiological advantage under the stress conditions.

\section{Acknowledgements}

The authors acknowledge Mrs. Andrea Jánošíková's help in proofreading this manuscript. Special thanks for valuable advice as well as help in research to Mgr. Veronika Kadličeková, $\mathrm{PhD}$.

\section{References}

Anderson, G. G., \& O'Toole, G. A. (2008). Innate and induced resistance mechanisms of bacterial biofilms. Current topics in microbiology and immunology, 322, 85-105. https://doi.org/10.1007/978-3-540-75418-3_5

Antelmann, H., Bernhardt, J., Schmid, R., Mach, H., Völker, U., \& Hecker, M. (1997). First steps from a two-dimensional protein index towards a response-regulation map for Bacillus subtilis. Electrophoresis. 1997;18(8):1451-1463. doi:10.1002/elps.1150180820

Aradska, J., Smidak, R., Turkovicova, L., Turna, J., \& Lubec, G. (2013). Proteomic differences between tellurite-sensitive and tellurite-resistant E.coli. PLoS One, 8(11), e78010. doi: 10.1371/journal.pone. 0078010 
410

411

412

413

414

415

416

417

418

419

420

421

422

423

424

425

426

427

428

429

430

431

432

433

434

435

436

437

438

439

440

441

442

443

444

445

446

447

448

449

450

451

452

453

454

455
Azeddoug, H., \& Reysset, G. (1994). Cloning and sequencing of a chromosomal fragment fromClostridium acetobutylicum strain ABKn8 conferring chemical-damaging agents and UV resistance toE. coli recA strains. Current Microbiology, 29(4), 229-235. doi: 10.1007/BF01570159

Basu, B., \& Apte, S. K. (2012). Gamma Radiation-induced Proteome of $<$ em $>$ Deinococcus radiodurans $<$ /em $>$ Primarily Targets DNA Repair and Oxidative Stress Alleviation. Molecular \&amp; Cellular Proteomics, 11(1), M111.011734. doi: 10.1074/mcp.M111.011734

Boddey, J. A., Flegg, C. P., Day, C. J., Beacham, I. R., \& Peak, I. R. (2006). Temperatureregulated microcolony formation by Burkholderia pseudomallei requires pilA and enhances association with cultured human cells. Infection and immunity, 74(9), 53745381. https://doi.org/10.1128/IAI.00569-06

Burian, J. B., J.; Macor, M.; Guller, L.; Siekel, P. (1990). Inducible resistance to tellurite in a human isolate of Escherichia coli. Biologia, 45(12), 1021-1026. Retrieved from https://eurekamag.com/research/007/449/007449576.php

Burian, J., Tu, N., Kl'ucar, L., Guller, L., Lloyd-Jones, G., Stuchlik, S., . . Turna, J. (1998). In vivo and in vitro cloning and phenotype characterization of tellurite resistance determinant conferred by plasmid pTE53 of a clinical isolate of Escherichia coli. Folia Microbiol (Praha), 43(6), 589-599. doi:10.1007/BF02816374

Caceres, S. M., Malcolm, K. C., Taylor-Cousar, J. L., Nichols, D. P., Saavedra, M. T., Bratton, D. L., Moskowitz, S. M., Burns, J. L., \& Nick, J. A. (2014). Enhanced in vitro formation and antibiotic resistance of nonattached Pseudomonas aeruginosa aggregates through incorporation of neutrophil products. Antimicrobial agents and chemotherapy, 58(11), 6851-6860. https://doi.org/10.1128/AAC.03514-14

Chen, Y. T., Chang, H. Y., Lai, Y. C., Pan, C. C., Tsai, S. F., \& Peng, H. L. (2004). Sequencing and analysis of the large virulence plasmid pLVPK of Klebsiella pneumoniae CG43. Gene, 337, 189-198. doi: 10.1016/j.gene.2004.05.008

Chen, C. Y., Chen, Y. H., Lu, P. L., Lin, W. R., Chen, T. C., \& Lin, C. Y. (2012). Proteus mirabilis urinary tract infection and bacteremia: risk factors, clinical presentation, and outcomes. J Microbiol Immunol Infect, 45(3), 228-236. doi:10.1016/j.jmii.2011.11.007

Dai, T., Vrahas, M. S., Murray, C. K., \& Hamblin, M. R. (2012). Ultraviolet C irradiation: an alternative antimicrobial approach to localized infections? Expert review of anti-infective therapy, 10(2), 185-195. doi: 10.1586/eri.11.166

Daigle, F., Lerat, S., Bucca, G., Sanssouci, E., Smith, C. P., Malouin, F., \& Beaulieu, C. (2015). A terD domain-encoding gene (SCO2368) is involved in calcium homeostasis and participates in calcium regulation of a DosR-like regulon in Streptomyces coelicolor. $J$ Bacteriol, 197(5), 913-923. doi: 10.1128/JB.02278-14

Peer] reviewing PDF | (2020:08:51726:3:0:NEW 24 Feb 2021) 
456

457

458

459

460

461

462

463

464

465

466

467

468

469

470

471

472

473

474

475

476

477

478

479

480

481

482

483

484

485

486

487

488

489

490

491

492

493

494

495

496

497

498

499

Daly, M. J., Ouyang, L., Fuchs, P., \& Minton, K. W. (1994). In vivo damage and recAdependent repair of plasmid and chromosomal DNA in the radiation-resistant bacterium Deinococcus radiodurans. Journal of bacteriology, 176(12), 3508-3517. doi: 10.1128/jb.176.12.3508-3517.1994

de Carvalho C. (2017). Biofilms: Microbial Strategies for Surviving UV Exposure. Advances in experimental medicine and biology, 996, 233-239. https://doi.org/10.1007/978-3-319$\underline{56017-5 \quad 19}$

Demeure, C., Dussurget, O., Fiol, G. M., Le Guern, A. S., Savin, C., \& Pizarro-Cerda, J. (2019). Yersinia pestis and plague: an updated view on evolution, virulence determinants, immune subversion, vaccination and diagnostics. Microbes Infect, 21(5-6), 202-212. doi:10.1016/j.micinf.2019.06.007

Elasri, M. O., \& Miller, R. V. (1999). Study of the response of a biofilm bacterial community to UV radiation. Applied and environmental microbiology, 65(5), 2025-2031. https://doi.org/10.1128/AEM.65.5.2025-2031.1999

Ghane, M., Babaeekhou, L., \& Ketabi, S. S. (2020). Antibiofilm Activity of Kefir Probiotic Lactobacilli Against Uropathogenic Escherichia coli (UPEC). Avicenna journal of medical biotechnology, 12(4), 221-229.

Grant, C. E., \& Tsang, A. (1990). Cloning and characterization of cDNAs encoding a novel cyclic AMP-binding protein in Dictyostelium discoideum. Gene, 96(2), 213-218. doi: 10.1016/0378-1119(90)90255-p

Gurzadyan, G. G., Görner, H., \& Schulte-Frohlinde, D. (1995). Ultraviolet (193, 216 and 254 $\mathrm{nm})$ photoinactivation of Escherichia coli strains with different repair deficiencies. Radiation research, 141(3), 244-251. doi: 10.2307/3579001

Haaber, J., Cohn, M. T., Frees, D., Andersen, T. J., \& Ingmer, H. (2012). Planktonic aggregates of Staphylococcus aureus protect against common antibiotics. PloS one, 7(7), e41075. https://doi.org/10.1371/journal.pone.0041075

Hall-Stoodley, L., Costerton, J. W., \& Stoodley, P. (2004). Bacterial biofilms: from the natural environment to infectious diseases. Nature reviews. Microbiology, 2(2), 95-108. https://doi.org/10.1038/nrmicro821

Hiramatsu, Y., Saito, M., Otsuka, N., Suzuki, E., Watanabe, M., Shibayama, K., \& Kamachi, K. (2016). BipA Is Associated with Preventing Autoagglutination and Promoting Biofilm Formation in Bordetella holmesii. PloS one, 11(7), e 0159999. https://doi.org/10.1371/journal.pone.0159999 
500

501

502

503

504

505

506

507

508

509

510

511

512

513

514

515

516

517

518

519

520

521

522

523

524

525

526

527

528

529

530

531

532

533

534

535

536

537

538

539

540

541

542

543

544

545

Jobling, M. G., \& Ritchie, D. A. (1988). The nucleotide sequence of a plasmid determinant for resistance to tellurium anions. Gene, 66(2), 245-258. doi: 10.1016/0378-1119(88)903617

Karlin, S., \& Mrazek, J. (2001). Predicted highly expressed and putative alien genes of Deinococcus radiodurans and implications for resistance to ionizing radiation damage. Proc Natl Acad Sci U S A, 98(9), 5240-5245. doi: 10.1073/pnas.081077598

Kormutakova, R., Klucar, L., \& Turna, J. (2000). DNA sequence analysis of the telluriteresistance determinant from clinical strain of Escherichia coli and identification of essential genes. Biometals, 13(2), 135-139. doi: 10.1023/a:1009272122989

Kostakioti, M., Hadjifrangiskou, M., \& Hultgren, S. J. (2013). Bacterial biofilms: development, dispersal, and therapeutic strategies in the dawn of the postantibiotic era. Cold Spring Harbor perspectives in medicine, 3(4), a010306. https://doi.org/10.1101/cshperspect.a010306

Kuczyńska-Wiśnik, D., Matuszewska, E., Furmanek-Blaszk, B., Leszczyńska, D., Grudowska, A., Szczepaniak, P., \& Laskowska, E. (2010). Antibiotics promoting oxidative stress inhibit formation of Escherichia coli biofilm via indole signalling. Research in microbiology, 161(10), 847-853. https://doi.org/10.1016/j.resmic.2010.09.012

Kwon, K. C., \& Cho, M. H. (2008). Deletion of the chloroplast-localized AtTerC gene product in Arabidopsis thaliana leads to loss of the thylakoid membrane and to seedling lethality. Plant J, 55(3), 428-442. doi: 10.1111/j.1365-313X.2008.03523.x

Lim, J. Y., Yoon, J., \& Hovde, C. J. (2010). A brief overview of Escherichia coli O157:H7 and its plasmid O157. J Microbiol Biotechnol, 20(1), 5-14. Retrieved from https://www.ncbi.nlm.nih.gov/pubmed/20134227

Liu, Y., Zhou, J., Omelchenko, M. V., Beliaev, A. S., Venkateswaran, A., Stair, J., Wu, L., Thompson, D. K., Xu, D., Rogozin, I. B., Gaidamakova, E. K., Zhai, M., Makarova, K. S., Koonin, E. V., \& Daly, M. J. (2003). Transcriptome dynamics of Deinococcus radiodurans recovering from ionizing radiation. Proceedings of the National Academy of Sciences of the United States of America, 100(7), 4191-4196. doi: 10.1073/pnas.0630387100

Makarova, K. S., Aravind, L., Wolf, Y. I., Tatusov, R. L., Minton, K. W., Koonin, E. V., \& Daly, M. J. (2001). Genome of the Extremely Radiation-Resistant Bacterium $<\mathrm{em}>$ Deinococcus radiodurans $</ \mathrm{em}>$ Viewed from the Perspective of Comparative Genomics. Microbiology and Molecular Biology Reviews, 65(1), 44-79. doi: 10.1128/mmbr.65.1.44-79.2001

Minton, K. W. (1994). DNA repair in the extremely radioresistant bacterium Deinococcus radiodurans. Molecular microbiology, 13(1), 9-15. doi: 10.1111/j.13652958.1994.tb00397.x 
546

547

548

549

550

551

552

553

554

555

556

557

558

559

560

561

562

563

564

565

566

567

568

569

570

571

572

573

574

575

576

577

578

579

580

581

582

583

584

585

586

587

588

589

590

591
Nelson, E. J., Harris, J. B., Morris, J. G., Jr., Calderwood, S. B., \& Camilli, A. (2009). Cholera transmission: the host, pathogen and bacteriophage dynamic. Nat Rev Microbiol, 7(10), 693-702. doi:10.1038/nrmicro2204

Ott, E., Kawaguchi, Y., Kolbl, D., Chaturvedi, P., Nakagawa, K., Yamagishi, A., ... Milojevic, T. (2017). Proteometabolomic response of Deinococcus radiodurans exposed to UVC and vacuum conditions: Initial studies prior to the Tanpopo space mission. PLoS One, 12(12), e0189381. doi: 10.1371/journal.pone.0189381

Pan, Y. R., Lou, Y. C., Seven, A. B., Rizo, J., \& Chen, C. (2011). NMR structure and calciumbinding properties of the tellurite resistance protein TerD from Klebsiella pneumoniae. $J$ Mol Biol, 405(5), 1188-1201. doi: 10.1016/j.jmb.2010.11.041

Pirnie, M., Linden, K., \& Malley, J. (2006). Ultraviolet disinfection guidance manual for the final long term 2 enhanced surface water treatment rule. Environmental Protection, 2, 1436.

Ponnusamy, D., \& Clinkenbeard, K. D. (2015). Role of Tellurite Resistance Operon in Filamentous Growth of Yersinia pestis in Macrophages. PloS one, 10(11), e0141984. https://doi.org/10.1371/journal.pone.0141984

Pope, C. F., O'Sullivan, D. M., McHugh, T. D., \& Gillespie, S. H. (2008). A practical guide to measuring mutation rates in antibiotic resistance. Antimicrobial agents and chemotherapy, 52(4), 1209-1214. doi: 10.1128/AAC.01152-07

Prigent-Combaret, C., Sanguin, H., Champier, L., Bertrand, C., Monnez, C., Colinon, C., Blaha, D., Ghigo, J. M., \& Cournoyer, B. (2012). The bacterial thiopurine methyltransferase tellurite resistance process is highly dependent upon aggregation properties and oxidative stress response. Environmental microbiology, 14(10), 2645-2660. https://doi.org/10.1111/j.1462-2920.2012.02802.x

Schroeder, G. N., \& Hilbi, H. (2008). Molecular pathogenesis of Shigella spp.: controlling host cell signaling, invasion, and death by type III secretion. Clin Microbiol Rev, 21(1), 134156. doi:10.1128/CMR.00032-07

Siede, W., Kow, Y.W., \& Doetsch, P. W. (2005). DNA Damage Recognition: CRC Press. ISBN 978-0-8493-5268-3

Shibai, A., Takahashi, Y., Ishizawa, Y., Motooka, D., Nakamura, S., Ying, B. W., \& Tsuru, S. (2017). Mutation accumulation under UV radiation in Escherichia coli. Scientific reports, 7(1), 14531. doi:10.1038/s41598-017-15008-1

Struve, C., \& Krogfelt, K. A. (2004). Pathogenic potential of environmental Klebsiella pneumoniae isolates. Environ Microbiol, 6(6), 584-590. doi:10.1111/j.14622920.2004.00590.x 
592 Sweet, D. M., \& Moseley, B. E. (1974). Accurate repair of ultraviolet-induced damage in

593

594

595

596

597

598

599

600

601

602

603

604

605

606

607

608

609

610

611

612

613

614

615

616

617

618

619

620

621

622

623

624

625

626

627

628

629

630

631

632

633

634

635

636

Micrococcus radiodurans. Mutation research, 23(3), 311-318. doi: 10.1016/00275107(74)90104-3

Tanaka, M., Earl, A. M., Howell, H. A., Park, M. J., Eisen, J. A., Peterson, S. N., \& Battista, J. R. (2004). Analysis of Deinococcus radiodurans's transcriptional response to ionizing radiation and desiccation reveals novel proteins that contribute to extreme radioresistance. Genetics, 168(1), 21-33. doi: 10.1534/genetics.104.029249

Taylor, D. E. (1999). Bacterial tellurite resistance. Trends Microbiol, 7(3), 111-115. doi: 10.1016/s0966-842x(99)01454-7

Taylor, D. E., Rooker, M., Keelan, M., Ng, L. K., Martin, I., Perna, N. T., . . . Blattner, F. R. (2002). Genomic variability of $\mathrm{O}$ islands encoding tellurite resistance in enterohemorrhagic Escherichia coli O157:H7 isolates. J Bacteriol, 184(17), 4690-4698. doi: $10.1128 /$ jb.184.17.4690-4698.2002

Toptchieva, A., Sisson, G., Bryden, L. J., Taylor, D. E., \& Hoffman, P. S. (2003). An inducible tellurite-resistance operon in Proteus mirabilis. Microbiology, 149(Pt 5), 1285-1295. doi: 10.1099/mic.0.25981-0

Tropp, B. E. (2008). Molecular Biology: Genes to Proteins: Jones and Bartlett Publishers. ISBN 978-0-7637-0916-7

Trunk, T., Khalil, H. S., \& Leo, J. C. (2018). Bacterial autoaggregation. AIMS microbiology, 4(1), 140-164. https://doi.org/10.3934/microbiol.2018.1.140

Turkovicova, L., Smidak, R., Jung, G., Turna, J., Lubec, G., \& Aradska, J. (2016). Proteomic analysis of the TerC interactome: Novel links to tellurite resistance and pathogenicity. $J$ Proteomics, 136, 167-173. doi: 10.1016/j.jprot.2016.01.003

Ye, Y., Zhang, M., Jiao, R., Ling, N., Zhang, X., Tong, L., Zeng, H., Zhang, J., \& Wu, Q. (2018). Inactivation of Cronobacter malonaticus cells and inhibition of its biofilm formation exposed to hydrogen peroxide stress. Journal of dairy science, 101(1), 66-74. https://doi.org/10.3168/jds.2017-13463

Wang, Z., Wang, J., Ren, G., Li, Y., \& Wang, X. (2015). Influence of Core Oligosaccharide of Lipopolysaccharide to Outer Membrane Behavior of Escherichia coli. Marine drugs, 13(6), 3325-3339. https://doi.org/10.3390/md13063325

Whelan, K. F., Sherburne, R. K., \& Taylor, D. E. (1997). Characterization of a region of the IncHI2 plasmid R478 which protects Escherichia coli from toxic effects specified by components of the tellurite, phage, and colicin resistance cluster. Journal of bacteriology, 179(1), 63-71. https://doi.org/10.1128/jb.179.1.63-71.1997 
Figure 1

Percentual survival after $120 \mathrm{~s}\left(300 \mathrm{~mJ} / \mathrm{cm}^{2}\right)$ exposure of UVC.

Note that after UV treatment, there was significant difference (t $(6)=5.60, p=0.0007$ ) between the percent survival of the Ter-positive group (Te-R) and Ter-negative group (control). Error values represent the standard deviation of experiments.

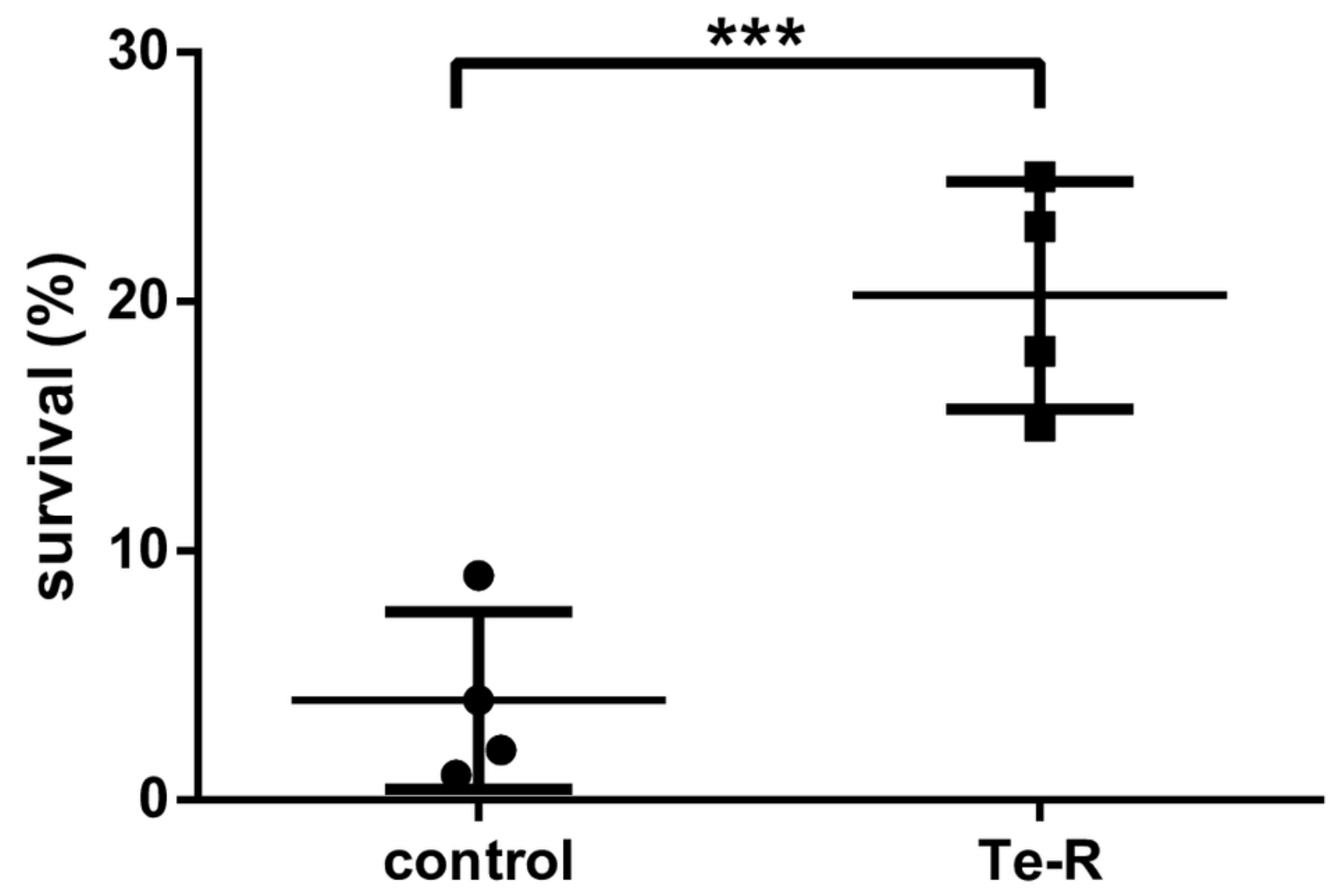


Figure 2

Ter-positive group (Te-R) is defective in biofilm formation compared with Ter-negative group (control) depending on Crystal Violet retention.

All statistical analyses were performed in GraphPad Prism 6.0 software by unpaired t-test. $* * * * P<0,0001$.

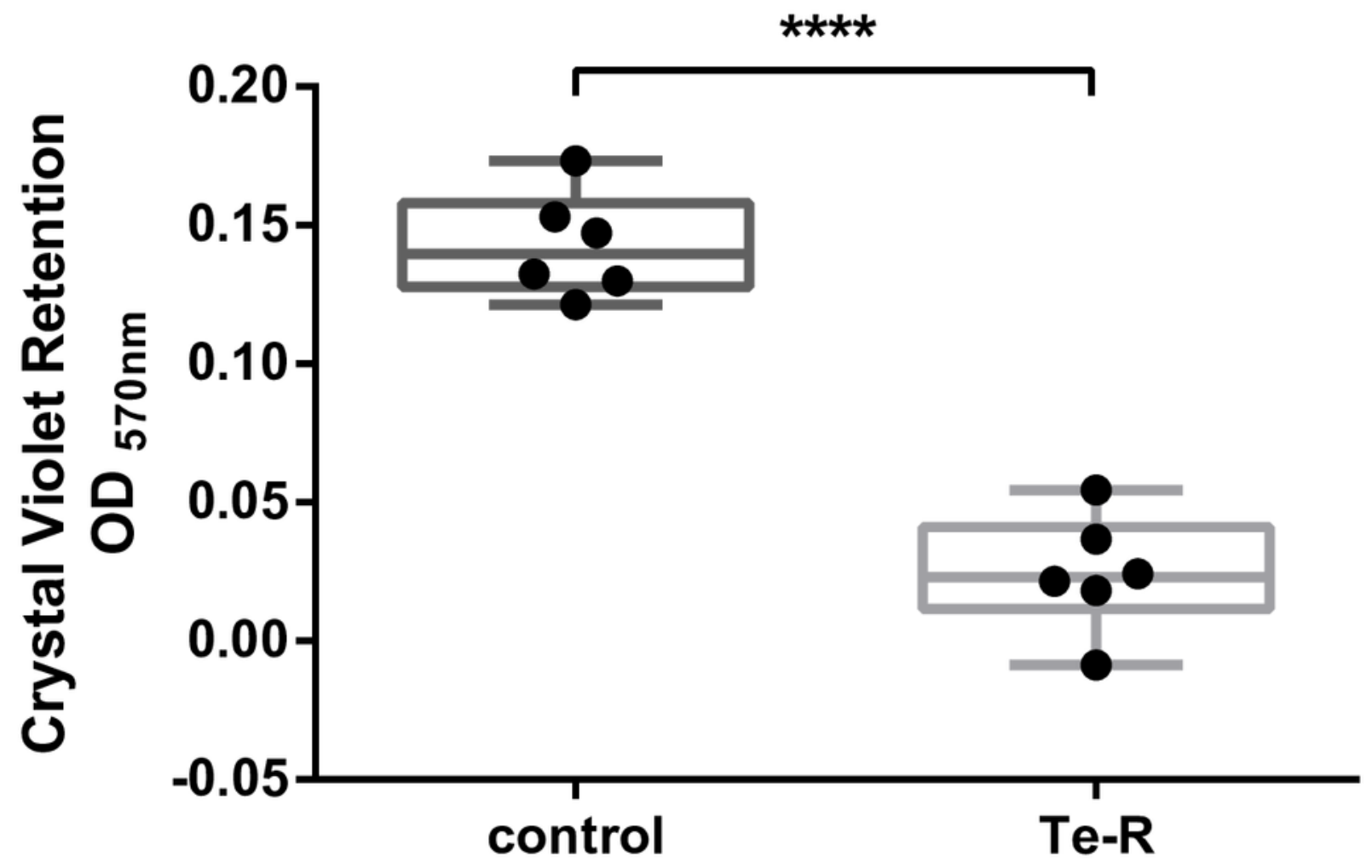


Figure 3

Ter-positive group (Te-R) is defective in biofilm formation compared with Ter-negative group (control) and Cronobacter malonaticus depending on Crystal Violet retention.

All statistical analyses were performed in GraphPad Prism 6.0 software by one-way ANOVA. $* * * * P<0.0001$.

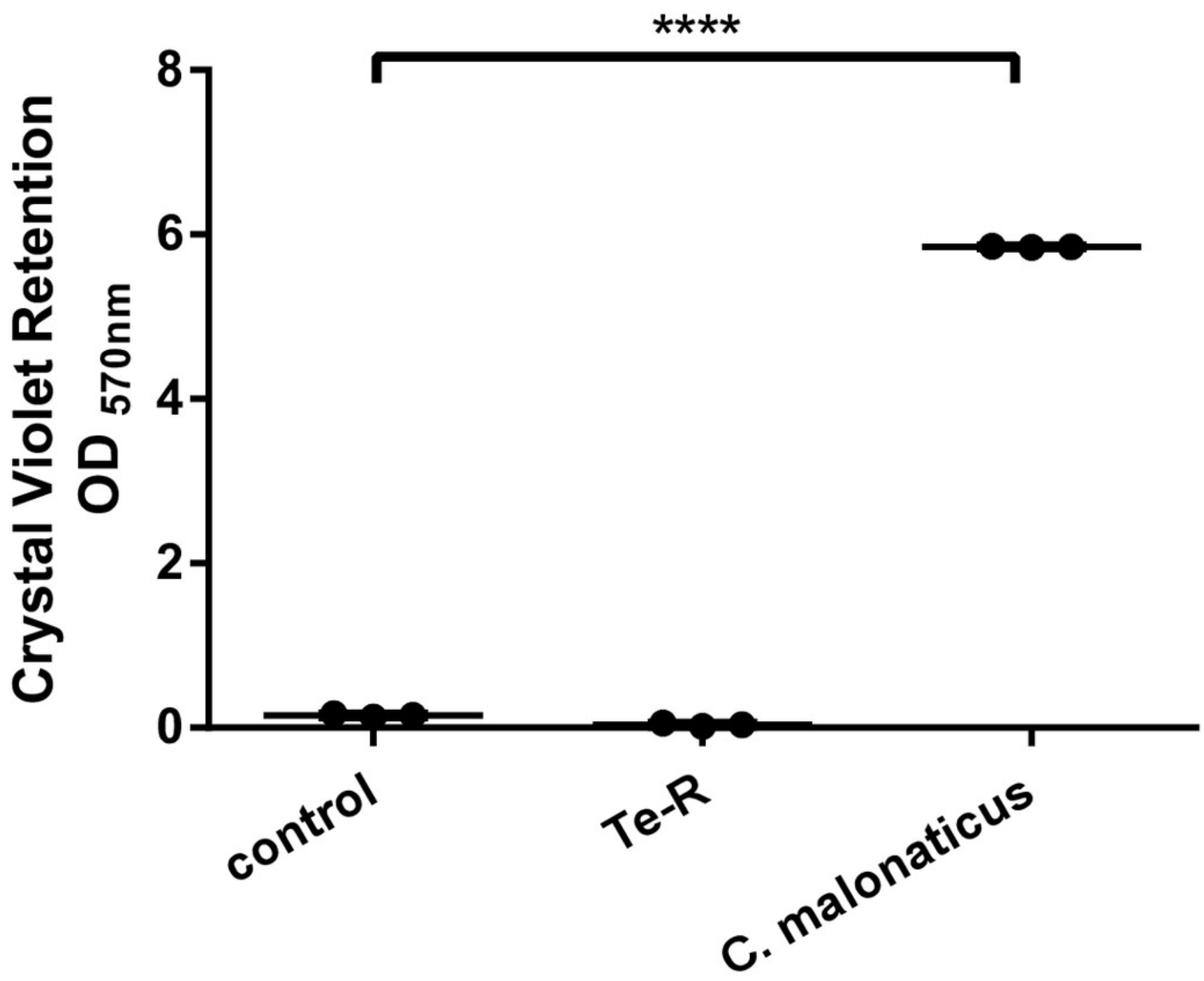


Table $\mathbf{1}$ (on next page)

Detailed mutation list of the Ter-positive and Ter-negative (control) strain after $120 \mathrm{~s}$ $\left(300 \mathrm{~mJ} / \mathrm{cm}^{2}\right)$ UVC exposure. 


\begin{tabular}{|l|l|l|l|l|l|l|l|l|l|l|l|l|l|l|l|l|}
\hline Strain & $\begin{array}{l}\text { Reference } \\
\text { Position }\end{array}$ & Gene & Type & Length & Reference & Allele & Zygosity & Count & Coverage & Frequency & $\begin{array}{l}\text { Forward/reverse } \\
\text { balance }\end{array}$ & $\begin{array}{l}\text { Average } \\
\text { quality }\end{array}$ & $\begin{array}{l}\text { Overlapping } \\
\text { annotations }\end{array}$ & $\begin{array}{l}\text { Coding } \\
\text { region } \\
\text { change }\end{array}$ & $\begin{array}{l}\text { Amino } \\
\text { acid } \\
\text { change }\end{array}$ \\
\hline $\begin{array}{l}\text { Ter- } \\
\text { negative }\end{array}$ & 330099 & cynX & Insertion & 1 & - & T & Homozygous & 46 & 89 & 51,68539326 & 0,478261 & 36,76087 & N/A & N/A & N/A \\
\hline $\begin{array}{l}\text { Ter- } \\
\text { negative }\end{array}$ & 3431701 & glgC & SNV & 1 & G & A & Homozygous & 39 & 75 & 52 & 0,493671 & 35,15385 & N/A & N/A & N/A \\
\hline $\begin{array}{l}\text { Ter- } \\
\text { positive }\end{array}$ & 160821 & pcnB & Deletion & 1 & T & - & Homozygous & 42 & 42 & 100 & 0,460317 & 35,57143 & N/A & N/A & N/A \\
\hline
\end{tabular}

